\title{
Mental disorder and clinical care in people convicted of homicide: national clinical survey
}

\author{
Jenny Shaw, Louis Appleby, Tim Amos, Ros McDonnell, Catherine Harris, Kerry McCann, \\ Katy Kiernan, Sue Davies, Harriet Bickley, Rebecca Parsons
}

\begin{abstract}
National
Confidential

Inquiry into Suicide and Homicide by People with Mental Illness, School of

Psychiatry and

Behavioural

Sciences, University of Manchester,

Withington

Hospital,

Manchester

M20 8LR

Jenny Shaw,

assistant director

Louis Appleby,

director

Tim Amos,

clinical research fellow

Ros McDonnell,

project manager

Catherine Harris,

research worker

Kerry McCann,

research worker

Katy Kiernan,

research assistant

Sue Davies,

research associate

Harriet Bickley,

research worker

Rebecca Parsons,

research worker

Correspondence to: Professor Appleby

Louis.Appleby@

man.ac.uk
\end{abstract}

BMJ 1999;318:1240-4

\begin{abstract}
Objectives To estimate the rate of mental disorder in those convicted of homicide and to examine the social and clinical characteristics of those with a history of contact with psychiatric services.

Design National clinical survey.

Setting England and Wales.

Subjects Eighteen month sample of people convicted of homicide.

Main outcome measures Offence related and clinical information collected from psychiatric court reports on people convicted of homicide. Detailed clinical data collected on those with a history of contact with psychiatric services.

Results 718 homicides were reported to the inquiry between April 1996 and November 1997. Of the 500 cases for whom psychiatric reports were retrieved, 220 (44\%; 95\% confidence interval $40 \%$ to $48 \%$ ) had a lifetime history of mental disorder, while 71 (14\%; $11 \%$ to $17 \%$ ) had symptoms of mental illness at the time of the homicide. Of the total sample, 102 (14\%; $12 \%$ to $17 \%$ ) were confirmed to have been in contact with mental health services at some time, $58(8 \% ; 6 \%$ to $10 \%$ ) in the year before the homicide. The commonest diagnosis was personality disorder (20 cases, $22 \% ; 13 \%$ to $30 \%$ ). Alcohol and drug misuse were also common. Only 15 subjects $(18 \% ; 10 \%$ to $26 \%$ ) were receiving intensive community care, and 60 $(63 \% ; 53 \%$ to $73 \%)$ were out of contact at the time of the homicide.

Conclusions There are substantial rates of mental disorder in people convicted of homicide. Most do not have severe mental illness or a history of contact with mental health services. Inquiry findings suggest that preventing loss of contact with services and improving the clinical management of patients with both mental illness and substance misuse may reduce risk, but clinical trials are needed to examine the effectiveness of such interventions.
\end{abstract}

\section{Introduction}

Recent public criticism of the community care of those with serious mental illness has been voiced on the basis of the reporting of certain high profile cases. ${ }^{1-3}$ However, reviews of the prevalence of mental illness in perpetrators of homicide ${ }^{45}$ have shown the difficulty of drawing conclusions about the relation between mental disorder and homicide, because of different definitions of mental disorder and because findings are rarely related to homicides in the general population. ${ }^{6}$ Similarly, little is known about the clinical care provided to those perpetrators in contact with psychiatric services before the homicide. Several policy initiatives have tried to improve the planning and coordination of community care. These include the care programme approach, which allocates patients with mental illness to different degrees of care according to their needs, those with highest priority having a key worker and receiving regular multidisciplinary review, ${ }^{7}$ and the supervision register, a national record of patients at highest risk of suicide or causing harm to others. ${ }^{8}$ In 1994 independent inquiries became mandatory after homicides by those in recent contact with mental health services. ${ }^{910}$ The value of these inquiries has been questioned, ${ }^{11}$ particularly regarding whether general lessons about service provision can be learnt and whether they inflame the so called culture of blame. $^{12}$

The national confidential inquiry into suicide and homicide by people with mental illness was established in 1992 and has been based at the University of Manchester since 1996. The homicide inquiry has two broad aims: firstly, to establish the frequency and contributory role of mental illness in a complete national sample of homicides; and, secondly, to examine aggregate data on those in contact with mental health services to inform clinical practice and policy. The specific objectives of data collection are:

- To establish in those convicted of homicide the lifetime rate of mental disorder according to psychiatric court reports, the rate of mental illness at the time of the offence as suggested by symptoms recorded in psychiatric court reports, and the rate of contact with mental health services

- To establish social, clinical, and forensic differences between those with mental illness at the time of the offence and those without, and specifically to compare their histories of violence and substance misuse and their relationship to their victims

- To examine the social and clinical characteristics of those with a history of contact with psychiatric services - To estimate the frequency of previous violence

- To estimate the proportion of patients convicted of homicide who had been given the highest priority under the care programme approach

- To estimate the frequency of key problems in service provision, including non-compliance with treatment and loss of contact with services

- To obtain the views of the mental health teams on how each homicide might have been prevented

This paper is the basis of a report to be published by the Department of Health. ${ }^{13}$ The report also includes findings on suicide, which are reported in the accompanying paper. ${ }^{14}$

\section{Subjects and methods}

Data collection on homicides had three stages: the collection of a comprehensive national sample of people convicted of homicide, irrespective of mental health history; identification of people in the sample who had 
Table 1 Rates of mental disorder in people convicted of homicide

\begin{tabular}{|c|c|c|c|c|}
\hline & Source & $\begin{array}{c}\text { No of people } \\
\text { convicted of } \\
\text { homicide }\end{array}$ & $\begin{array}{c}\% \text { of all homicides; } \\
95 \% \mathrm{Cl}(\mathrm{n}=718)\end{array}$ & $\begin{array}{l}\% \text { of homicides } \\
\text { with psychiatric } \\
\text { report }(n=500)\end{array}$ \\
\hline Convicted of section 2 manslaughter (diminished responsibility) & Homicide index & 69 & $10(7$ to 12$)$ & \\
\hline Hospital order & Homicide index & 46 & $6(5$ to 8$)$ & \\
\hline Mental disorder during lifetime & Psychiatric reports & 220 & 31 (27 to 34$)$ & $44(40$ to 48$)$ \\
\hline Schizophrenia during lifetime & Psychiatric reports & 30 & 4 (3 to 6$)$ & $6(4$ to 8$)$ \\
\hline Abnormal mental state at time of offence & Psychiatric reports & 71 & 10 (8 to 12$)$ & $14(11$ to 17$)$ \\
\hline \multicolumn{5}{|l|}{ Contact with mental health services: } \\
\hline During lifetime & Mental health case records & 102 & $14(12$ to 17$)$ & \\
\hline 1 year before offence & Mental health case records & 58 & $8(6$ to 10$)$ & \\
\hline
\end{tabular}

been in contact with mental health services; and the collection of clinical data on these people.

Comprehensive national sample-Information on all those convicted of homicide was forwarded regularly to the inquiry from the homicide index at the Home Office. This included demographic details of perpetrator and victim, method and circumstances of the killing, court of trial, and outcome of the trial and disposal. We acquired the psychiatric reports prepared for the Crown (and defence if present in files) from the court of trial and a list of previous convictions from the police. We supplemented our sample of psychiatric reports from records held by other agencies concerned with the trial, sentencing, and psychiatric assessment or health care of offenders-namely, the Crown Prosecution Service, the life sentences section and mental health unit at the Home Office, prison healthcare services, and individual forensic psychiatrists. We obtained demographic details, history of drug and alcohol misuse, previous contact with psychiatric services, psychiatric diagnosis, and mental state abnormalities at the time of the offence from the psychiatric reports.

Identification of mental health service contact-Two methods were used to determine whether the perpetrator had ever been in contact with mental health services. Firstly, when this was referred to in the psychiatric report, the hospital concerned was contacted and the responsible psychiatrist was identified. Secondly, for each perpetrator, identifying details were submitted to all hospitals providing mental health care to residents of his or her health district. The person became an inquiry case if there had been contact with psychiatric services at any time. An assessment of the accuracy of hospital checks showed that $97 \%$ of patients in contact with services in the previous year were detected. ${ }^{14}$ Individual reporting arrangements were agreed with national, regional, and private hospital units.

Collection of clinical data-For each inquiry case the responsible psychiatrist was sent a questionnaire and asked to complete it in conjunction with members of the mental health team. The questionnaire consisted of sections covering demographic details, clinical history, details of the care of inpatients who commit homicide, details of the care of community patients who commit homicide, details of final contact with services, and respondents' views on prevention. The clinical history section included questions on previous violence.

Statistical analysis-The main estimates, such as rates of mental disorder and key social and clinical characteristics, are presented as proportions with 95\% confidence intervals. Percentages were based on valid cases-that is, those for whom an item of information was known. Comparisons of subsamples were carried out by $\chi^{2}$ tests, with significance generally set at $\mathrm{P}=0.01$.

\section{Results}

All homicides-From April 1996 to November 1997 we were notified of 718 homicide convictions from the homicide index. Six hundred and forty four (90\%) were male. The median age was 27 years (range 10-77 years). Five hundred and thirty four $(74 \%)$ victims were men. Two hundred and twenty one $(35 \%)$ perpetrators killed family members and $165(26 \%)$ killed a stranger. The commonest method of killing was stabbing (277 cases, 39\%). Sixty nine (10\%) were found guilty of manslaughter on the grounds of diminished responsibility and $46(6 \%)$ were sent to psychiatric hospital. We obtained details of previous convictions in $696(97 \%)$

Table 2 Social and clinical characteristics of people with psychiatric reports who committed homicide, according to presence of mental disorder at time of homicide. Values are proportions (percentages) of subjects unless stated otherwise

\begin{tabular}{|c|c|c|c|}
\hline & $\begin{array}{c}\text { Mental } \\
\text { disorder }(\mathrm{n}=71)\end{array}$ & $\begin{array}{c}\text { No mental disorder } \\
(\mathrm{n}=429)\end{array}$ & $P$ value \\
\hline \multicolumn{4}{|l|}{ Social and demographic variables } \\
\hline Median age (range) (years) & $34(19-77)$ & $27(13-67)$ & 0.000 \\
\hline Not currently married & $40 / 70(57)$ & $255 / 400(64)$ & 0.290 \\
\hline Unemployed & $36 / 71(51)$ & $222 / 394(57)$ & 0.430 \\
\hline Living alone & $10 / 68(15)$ & $52 / 337(15)$ & 0.910 \\
\hline Homeless or no fixed abode & $0 / 69$ & $15 / 352(4)$ & 0.080 \\
\hline \multicolumn{4}{|l|}{ Clinical variables } \\
\hline History of alcohol misuse & $25 / 68(37)$ & $155 / 391(40)$ & 0.650 \\
\hline Alcohol thought to have contributed to the offence & $21 / 69(30)$ & 189/343 (55) & 0.000 \\
\hline History of drug misuse & $15 / 68(22)$ & 144/388 (37) & 0.016 \\
\hline Drugs thought to have contributed to the offence & $5 / 69(7)$ & $69 / 351(20)$ & 0.013 \\
\hline \multicolumn{4}{|l|}{ Service contact } \\
\hline \multicolumn{4}{|l|}{ Contact with psychiatric services: } \\
\hline Any contact (lifetime) & $21 / 71(30)$ & $62 / 429(14)$ & 0.002 \\
\hline Contact in last year & $14 / 71(20)$ & $33 / 429(8)$ & 0.211 \\
\hline \multicolumn{4}{|l|}{ Offence variables } \\
\hline Median age of victim (range) (years) & $39(0-87)$ & $34(0-89)$ & 0.352 \\
\hline Male victim & $30 / 71(42)$ & $328 / 429(76)$ & 0.000 \\
\hline Victim was stranger & $5 / 68(7)$ & $94 / 377(25)$ & 0.001 \\
\hline Sharp instrument used & $33 / 71(46)$ & 174/424 (41) & 0.390 \\
\hline \multicolumn{4}{|l|}{ Final outcome: } \\
\hline Murder & $6 / 71(8)$ & $249 / 429(58)$ & 0.000 \\
\hline \multicolumn{4}{|l|}{ Manslaughter: } \\
\hline Diminished responsibility & $44 / 71(62)$ & $25 / 429(6)$ & 0.000 \\
\hline Other, including provocation and self defence & $18 / 71(25)$ & $152 / 429(35)$ & 0.000 \\
\hline Infanticide & $3 / 71(4)$ & $2 / 429(1)$ & 0.000 \\
\hline \multicolumn{4}{|l|}{ Disposal: } \\
\hline Prison & $32 / 71(45)$ & $410 / 429(96)$ & 0.000 \\
\hline Hospital order with or without restriction & $34 / 71(48)$ & $11 / 429(3)$ & 0.000 \\
\hline Other & $5 / 71(7)$ & $8 / 429(2)$ & 0.000 \\
\hline
\end{tabular}


Table 3 Social and clinical data on people convicted of homicide who had been in contact with mental health services at any time and in the 12 months before the homicide. Values are proportions (percentages; 95\% confidence intervals) of people unless stated otherwise

\begin{tabular}{|c|c|c|}
\hline & $\begin{array}{c}\text { Contact at any time } \\
(\mathrm{n}=95)\end{array}$ & $\begin{array}{l}\text { Contact within } 12 \text { months } \\
\qquad(\mathrm{n}=54)\end{array}$ \\
\hline \multicolumn{3}{|l|}{ Social and demographic variables } \\
\hline Median age (range) (years) & $30(14-58)$ & $30(14-53)$ \\
\hline Male sex & $76 / 95(80 ; 72$ to 88$)$ & $43 / 54(80 ; 69$ to 90$)$ \\
\hline Member of ethnic minority group & $6 / 94(6 ; 1$ to 11$)$ & $3 / 54(6 ; 0$ to 12$)$ \\
\hline Not currently married & $62 / 82(76 ; 66$ to 85$)$ & $41 / 52(79 ; 68$ to 90$)$ \\
\hline Unemployed & $53 / 78(68 ; 58$ to 78$)$ & $35 / 53(66 ; 53$ to 79$)$ \\
\hline Living alone & $32 / 72(44 ; 33$ to 56$)$ & $20 / 49(41 ; 27$ to 55$)$ \\
\hline \multicolumn{3}{|l|}{ Clinical variables } \\
\hline \multicolumn{3}{|l|}{ Primary diagnosis: } \\
\hline Schizophrenia and other delusional disorder & $15 / 91(16 ; 9$ to 24$)$ & $12 / 52(23 ; 12$ to 35$)$ \\
\hline Affective disorder (bipolar and depression) & $10 / 91(11 ; 5$ to 17$)$ & $4 / 52(8 ; 0$ to 15$)$ \\
\hline Neurotic disorder & $5 / 91(5 ; 1$ to 10$)$ & $2 / 52(4 ; 0$ to 9$)$ \\
\hline Alcohol dependence & $14 / 91(15 ; 8$ to 23$)$ & $7 / 52(13 ; 4$ to 23$)$ \\
\hline Drug dependence & $12 / 91(13 ; 6$ to 20$)$ & $9 / 52(17 ; 7$ to 28$)$ \\
\hline Personality disorder & $20 / 91$ (22; 13 to 30$)$ & $10 / 52(19 ; 9$ to 30$)$ \\
\hline Other & $15 / 91$ (16; 9 to 24$)$ & $8 / 52(15 ; 6$ to 25$)$ \\
\hline Any secondary diagnosis: & $50 / 91(55 ; 45$ to 65$)$ & $29 / 52(56 ; 42$ to 69$)$ \\
\hline Affective disorder (bipolar and depression) & $6 / 91(7 ; 1$ to 12$)$ & $4 / 52(8 ; 0$ to 15$)$ \\
\hline Neurotic disorder & $5 / 91(5 ; 1$ to 10$)$ & $2 / 52(4 ; 0$ to 9$)$ \\
\hline Alcohol dependence & $14 / 91$ (15; 8 to 23$)$ & $7 / 52(13 ; 4$ to 23$)$ \\
\hline Drug dependence & $13 / 91(14 ; 7$ to 21$)$ & $6 / 52(12 ; 3$ to 20$)$ \\
\hline Personality disorder & $21 / 91$ (23; 14 to 32$)$ & $17 / 52$ (33; 20 to 45$)$ \\
\hline Other & $4 / 91(4 ; 0$ to 9$)$ & $1 / 52(2 ; 0$ to 6$)$ \\
\hline Duration of history $<12$ months & $9 / 89(10 ; 4$ to 16$)$ & $9 / 50(18 ; 7$ to 29$)$ \\
\hline More than 5 previous admissions & $10 / 92(11 ; 5$ to 17$)$ & $7 / 52(13 ; 4$ to 23$)$ \\
\hline History of self harm & $47 / 89(53 ; 42$ to 63$)$ & $31 / 51(61 ; 47$ to 74$)$ \\
\hline History of alcohol misuse & $62 / 89(70 ; 60$ to 79$)$ & $38 / 51(75 ; 63$ to 86$)$ \\
\hline History of drug misuse & $55 / 85(65 ; 55$ to 75$)$ & $33 / 49(67 ; 54$ to 80$)$ \\
\hline \multicolumn{3}{|l|}{ Service contact } \\
\hline Symptoms at last contact with services & $43 / 93(46 ; 36$ to 56$)$ & $21 / 52(40 ; 27$ to 54$)$ \\
\hline Estimate of risk at final contact was low (or none) & $68 / 77(88 ; 81$ to 95$)$ & $45 / 48(94 ; 87$ to 100$)$ \\
\hline Homicide thought to be preventable & $8 / 65$ (12; 4 to 20$)$ & $5 / 45(11 ; 2$ to 20$)$ \\
\hline
\end{tabular}

cases. Of these, $258(37 \%)$ had a history of violence against the person. We obtained psychiatric reports in $500(70 \%)$ cases. Reports were more likely to be obtained when the perpetrator was found guilty of manslaughter on the grounds of diminished responsibility (69 cases (14\%) with reports, none without reports) and committed to hospital (45 cases $(9 \%)$ with reports, 1 case $(0.5 \%)$ without report).

Rates of mental disorder-Table 1 shows different estimates of the rate of mental disorder in those convicted of homicide.

Homicides and lifetime history of mental disorder-In 220 cases (44\%; 95\% confidence interval 40\% to 48\%) a diagnosis of mental disorder was specified in psychiatric court reports on the basis of lifetime histories. The commonest diagnoses were affective disorders (53 cases, $11 \% ; 8 \%$ to $13 \%)$ and personality disorder (47 cases, $9 \% ; 7 \%$ to $12 \%)$. Thirty $(6 \% ; 4 \%$ to $8 \%)$ had a diagnosis of schizophrenia. Only $40(18 \% ; 13 \%$ to $23 \%)$ people with a lifetime history of mental disorder were in contact with psychiatric services in the year before the offence.

Homicides by people with mental illness at the time of the offence-Seventy one perpetrators (14\%; $11 \%$ to $17 \%)$ were noted in the psychiatric reports to have had symptoms of mental illness at the time of the homicide. These were most commonly symptoms of depression (48 cases), while 27 had delusions or hallucinations, or both, indicating psychotic illness. Table 2 shows the characteristics of the mentally ill group in comparison with those without symptoms. Those who were mentally ill had a lower rate of drug misuse, alcohol and drugs were less likely to have played a part in the offence, and they had a significantly lower rate of previous convictions for violence against the person $\left(17 \% v 41 \%, \chi^{2}{ }_{1}=15.90\right.$, $\mathrm{P}<0.001)$. Their victims were more likely to be a family member or a spouse or partner and less likely to be a stranger. Only $14(20 \% ; 10 \%$ to $29 \%)$ had been in contact with mental health services in the previous year.

Inquiry cases-Of the total sample, 102 perpetrators $(14 \% ; 12 \%$ to $17 \%)$ were known to have been in contact with mental health services at any time, $58(8 \% ; 6 \%$ to $10 \%$ ) in the 12 months before the offence. We received completed questionnaires in 95 cases, a response rate of $93 \%$; the findings refer to these cases. Table 3 shows the social and clinical characteristics of the inquiry cases, including separately those whose contact with services occurred within 12 months of the offence. As with homicides in the general population, most perpetrators were male, single, and unemployed. The commonest diagnoses were personality disorder and schizophrenia. Alcohol or drug misuse, or both, were present in most cases.

History of violence -Forty two inquiry cases had previous convictions for violence. Twenty two of these had a history of violence documented in the case notes. A further eight inquiry cases had no previous convictions for violence, but a history of violence was documented in the case notes. In total, therefore, 50 patients $(53 \%$; $43 \%$ to $63 \%$ ) had a documented history of violence.

Clinical care-Only 15 (18\%; $10 \%$ to $26 \%)$ patients had been given highest priority under the care programme approach, including 12 patients $(22 \%$; $11 \%$ to $33 \%$ ) who had been in contact in the previous year and 9 of the 15 patients with a diagnosis of schizophrenia $(60 \% ; 35 \%$ to $85 \%)$. Two patients were on the supervision register. Most patients were receiving some form of drug treatment, but 18 of those in contact in the year before the homicide ( $44 \%$ of those in whom compliance was known to staff; $29 \%$ to $59 \%$ ) were said not to be fully compliant with their drug treatment plan. Sixty $(71 \%$; $61 \%$ to $80 \%)$ patients were out of contact with services at the time of the homicide. In 40 $(67 \% ; 55 \%$ to $79 \%)$ this followed self discharge or discharge as a result of patient actions; in $12(30 \% ; 6 \%$ to $20 \%$ ) of these cases no further action was taken by services after loss of contact.

Final contact with services-The last contact with services occurred less than 13 weeks before the homicide in 31 (33\%; 23\% to 42\%) cases and during the week before the homicide in $12(13 \% ; 6 \%$ to $20 \%)$. Immediate risk was thought to be low or absent in 68 ( $88 \%$ of those for whom risk estimation was known; $81 \%$ to $95 \%$ ).

Prevention-Mental health teams regarded the homicides as preventable in only 8 cases $(12 \% ; 4 \%$ to $20 \%)$, although $40(42 \% ; 32 \%$ to $52 \%)$ specified measures that could have reduced the risk, particularly better compliance with treatment (24 cases, $25 \% ; 17 \%$ to $34 \%$ ).

\section{Discussion}

Rates of mental disorder

The rate of mental disorder in perpetrators of homicide cannot be measured directly, and our 
findings present different ways of estimating this based on lifetime history, symptoms at offence, court disposal, or contact with mental health services (table 1). These estimates are higher than quoted figures for mental disorder in the general population, ${ }^{15}$ although directly comparable figures are not available, and each estimate is open to criticism. For example, the rate of $14 \%$ with mental illness at the time of the offence is likely to be an overestimate because this is the rate in those for whom psychiatric reports were available to the study. However, even if none of the unobtainable reports included evidence of mental disorder, the overall rate would still seem high at $10 \%$. In addition, the authors of psychiatric reports may overdiagnose depression to effect a more lenient outcome in court. For this reason we required clear evidence of persistent depressive illness and did not accept a diagnosis of depression if this appeared only in a report prepared for the defence. Similarly, the rate of $14 \%$ who had had previous contact with services is likely to exclude contacts that occurred many years ago or in services at a distance from where the perpetrator was living at the time of the offence. The rate of verdicts of diminished responsibility reflects the processes of the criminal justice system rather than the true rate of mental disorder, particularly when perpetrators have a personality disorder. $^{16}$

However, three conclusions can be drawn. Firstly, there is a substantial rate of mental disorder in people convicted of homicide, according to psychiatric court reports. Secondly, most disorders are not of serious mental illness, if this is broadly defined as patients with schizophrenia or depression of a severity that leads to contact with specialist services. Thirdly, most people with mental disorder who are convicted of homicide have not been in contact with mental health services. Among the people who had been in contact with psychiatric services the commonest diagnosis was personality disorder. The issue of whether people with personality disorder should be treated in hospital or imprisoned has recently been highlighted, ${ }^{17-20}$ and there is a need for guidelines about what mental health services can expect to achieve with this group of patients. Similarly, alcohol and drug misuse were common in our sample and any public health strategy for preventing homicide would have to focus on these at least as much as on mental illness.

\section{Methodological issues}

The national confidential inquiry is in part a survey of clinical care, and important limitations of its methods must be emphasised. Firstly, the absence of a control group means that it cannot draw aetiological conclusions. Secondly, the clinicians providing information may be biased by awareness of outcome. Thirdly, the questionnaires have not been formally tested for reliability and validity. Nevertheless, it is clearly a matter of concern that only a small proportion of patients who committed homicide were given priority care under the care programme approach and that many were out of contact with services at the time of the homicide. This was true of the whole sample but also of those with severe mental illness. There is evidence that contact with patients is more effectively maintained by intensive community support (assertive outreach), ${ }^{21}$ although whether this
Key messages

- People convicted of homicide have substantial rates of mental disorder

- Most do not have severe mental illness or a history of contact with mental health services

- Mental health services need to prevent loss of contact with patients

- The clinical management of patients with both mental illness and substance misuse needs to be improved

leads to a lowering of the risk of serious violence has not been assessed. Similarly, the high rates of drug and alcohol misuse in this sample imply the need for services that are able to treat both mental illness and substance misuse, ${ }^{22}$ although it is not known whether such services would be able to reduce the risk of violence.

\section{Prevention of homicide}

These findings suggest several ways of reducing risk in clinical practice for which further evidence of effectiveness is now needed and are the basis of recommendations for mental health services to be published in a Department of Health report. ${ }^{13}$ They also help to clarify the relation between community care and homicide. Our data correspond to around 40 homicides per year in people who have been in contact with mental health services in the previous 12 months. This is a small proportion of the total number of homicides annually and a fraction of the number of psychiatric patients, but it is not insignificant, and improving the safety of mental health services should remain a priority. However, only a few of these cases have severe mental illness, and the limitation of what treatment by mental health services alone can achieve in preventing homicides should be recognised.

We acknowledge the help of the Home Office, Lord Chancellor's Office; Crown Prosecution Service; the prison health care service; the prison section for prisoners with life sentences; David Westwood, Deputy Chief Constable, Humberside Police; the National Crime Faculty; the chief clerks at the Crown courts in England; Crown court and trust contacts; consultant psychiatrists for completing the questionnaires; and Professor Graham Dunn, Professor of Biostatistics, University of Manchester for his comments on the presentation of the statistical analysis.

Contributors: LA and JS were grant holders and led the design and coordination of the project, data collection, analysis of data, and the writing of the paper. TA and RM contributed to the design of the study and the coordination of data collection, project management, and analysis. $\mathrm{CH}, \mathrm{KM}, \mathrm{SD}, \mathrm{HB}$, and RP contributed to data collection and data management. KK contributed to data management and analysis. All authors approved the final version of the paper. LA is guarantor for the study.

Funding: Department of Health; Welsh Office.

Competing interests: None declared.

1 Hinsliff G. A new way of caring. Action on mental patients who are a danger to society. Daily Mail 1998:27 (col 1).

2 Davies N. Another tragic failure for community care. Guardian 1998 July 14:2-3 (col 1).

3 Gilla A, Campbell D. Dark secrets of the Russell killer. Guardian 1998 Oct 24:1 ( $\operatorname{col} 1)$.

4 Taylor PJ, Gunn J. Homicides by people with mental illness: Myth and reality. Br J Psychiatry 1999;174:9-14.

5 Petursson H, Gudjjusson GH. Psychiatric aspects of homicide. Acta Psychiatr Scand 1981;64:363-72.

6 Coid J. The epidemiology of abnormal homicide and murder followed by suicide. Psychol Med 1983;13:855-60. 
7 Department of Health. The care programme approach for people with a mental illness referred to the specialist psychiatric services. London: DoH, 1990. (Circular HC(90)23/LASSL(90)1.)

8 Department of Health. Introduction of the supervision registers for mentally ill people from April 1994. London: DoH, 1994. (Circular HSG(95)5.)

9 Department of Health. Guidance on the discharge of mentally disordered people and their continuing care in the community. London: HMSO, 1994.

10 Department of Health. Building bridges. A guide to arrangements for interagency working for the care and protection of seriously mentally ill people. London: HMSO, 1995.

11 Peay J. Inquiries after homicide. London: Duckworth, 1996.

12 Peay J. Clinicians and inquiries: demons, drones or demigods? Int Rev Psychiatry 1997;9:171-7.

13 Appleby L, Shaw J, Amos T, McDonnell R, Kiernan K, Davies S, et al. Safer services. Report of the national confidential inquiry into suicide and homicide by people with mental illness. London: Stationery Office, 1999.

14 Appleby L, Shaw J, Amos T, McDonnell R, Harris C, McCann K, et al. Suicide within 12 months of contact with mental health services: national clinical survey. BMJ 1999;318:1235-9.
15 Meltzer H, Gill B, Petticrew M, Hinds K. The prevalence of psychiatric morbidity among adults living in private households. London: HMSO, 1995. (OPCS Surveys of Psychiatric Morbidity in Great Britain. Report 1.)

16 Cope RA. Survey of forensic psychiatrists' views on psychopathic disorder. J Forens Psychiatry 1993;4:215-36.

17 Straw J. Straw's reposte on mental treatment. Times 1998 Oct 31:27.

18 Kendell R. Jack Straw and police under fire after Stone verdict. Times 1998 Oct 29:25.

19 Fallon P, Bluglass R, Edwards B, Daniels G. Report of the committee of inquiry into complaints about Ashworth Hospital. London: Stationery Office, 1999.

20 Eastman N. Who should take responsibility for antisocial personality disorder? BMJ 1999;318:206-7.

21 Burns BJ, Santo AB. Assertive community treatment: an update of randomized trials. Psychiatr Serv 1995;46:669-75.

22 Weaver T, Renton A, Stimson G, Tyrer P. Severe mental illness and substance misuse. BMJ 1999;318:137-38.

(Accepted 24 March 1999)

\title{
Effect of screening on cervical cancer mortality in England and Wales: analysis of trends with an age period cohort model
}

\author{
Peter Sasieni, Joanna Adams
}

Correspondence to: Dr Sasieni p.sasieni@icrf.icnet.uk

continued over

BMJ 1999;318:1244-5
The number of women dying from cervical cancer in 1997 was 7\% lower than in 1996 and has fallen by over $25 \%$ since 1992. ${ }^{1}$ Such rapid change must be at least partly due to cervical screening, although strong cohort effects have caused large fluctuations in cervical
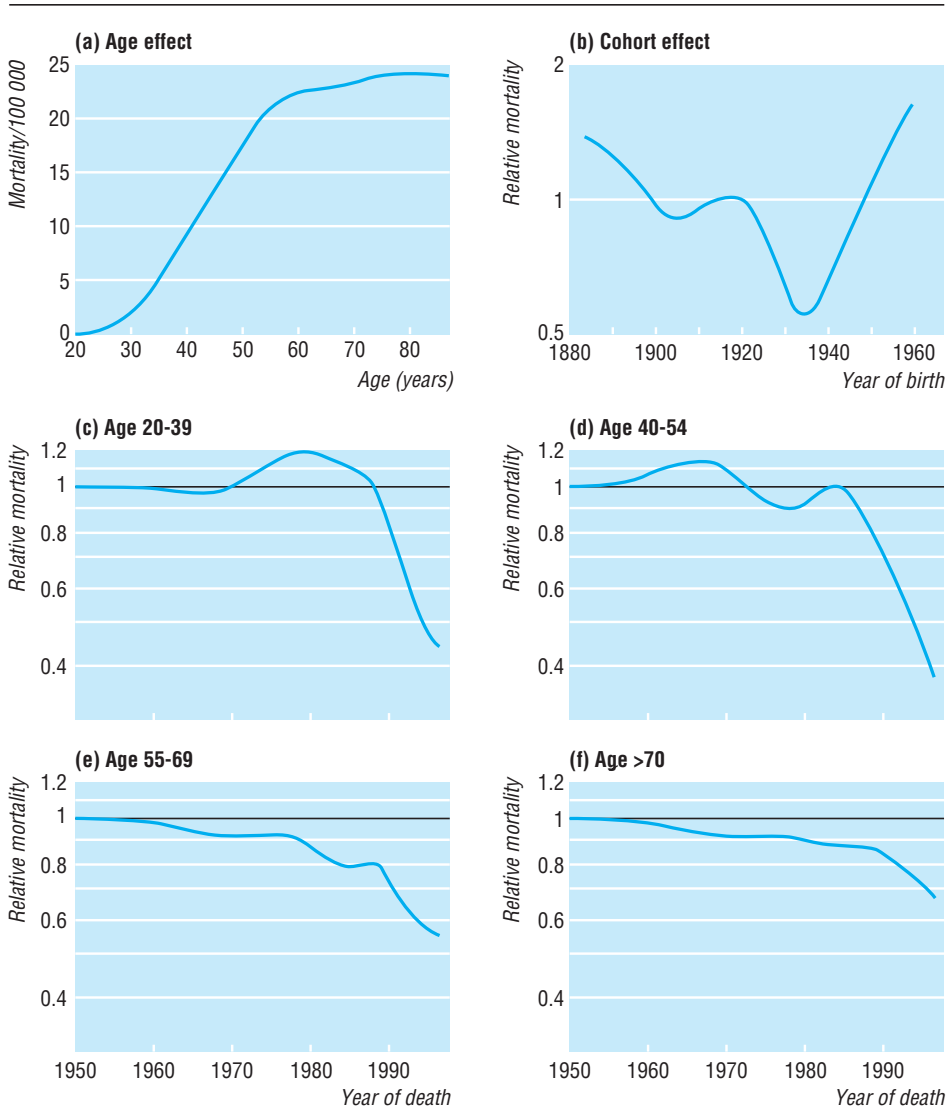

Effect of age (a) and year of birth (b) on mortality from cervical cancer and trends in mortality after age and cohort effects were adjusted for in four age groups (c- $f$ ) mortality in the past. ${ }^{2}$ We modelled mortality data, taking into account the effects of age and year of birth and looking for trends in time within four age groups to estimate the beneficial effects of cervical screening.

\section{Subjects, methods, and results}

We obtained mortality data, in 5 year age bands, from death registrations in England and Wales and calculated rates using mid-year population estimates. Mortality since 1993 was adjusted upwards by $4 \%$ because of changes in classification of cause of death. ${ }^{3}$

We modelled the data assuming that the age specific mortality is the product of a smoothly varying age effect, birth cohort effect, and age dependent period effects. Confidence intervals are approximate. Details of the statistical modelling are available from the authors on request.

The top of the figure shows the estimated underlying mortality for cervical cancer as a function of age (a) and the multiplicative effect of year of birth on the age specific rate (b). Compared with women born in 1922, the risk for those born in 1957 is increased 1.5 times (95\% confidence interval 1.2 to 1.9). The increased risk in women born since 1935 coincides with changing sexual behaviour associated with the "swinging ' 60 s" and the widespread use of oral contraceptives in the early 1970 s.

The bottom of the figure (c-f) shows the trends in cervical cancer mortality after age and cohort effects were accounted for. No significant trends occurred in mortality before the mid-1980s, but mortality subsequently fell progressively (and significantly). The reduction in relative risk was greatest in the youngest age groups and least in those aged over 70 years.

If it is assumed that a model using only age and birth cohort effects would fit the data adequately if there had been no screening, then the estimated age and birth cohort effects can be used to predict what the 